\title{
Metal-catalysed Hydration of 2-Pyridyloxiran
}

\author{
By Robert P. Hanzlik* and William J. Michaely \\ (Department of Medicinal Chemistry, University of Kansas, Lawrence, Kansas 66045)
}

Summary In the presence of $\mathrm{Cu} I I$ the hydration of 2pyridyloxiran is accelerated 18,000-fold, and its reaction with $\mathrm{Cl}^{-}, \mathrm{Br}^{-}$, and $\mathrm{MeO}^{-}$becomes $100 \%$ regiospecific for $\beta$-attack.

METAL ions in aqueous solution, particularly $\mathrm{Cu} I I, \mathrm{NiII}$, and $\mathrm{ZnII}$, are powerful catalysts for the hydrolysis of coordinated esters and amides. ${ }^{1}$ We now report that this catalytic ability extends to include epoxide hydration as well and that the reaction of co-ordinated epoxides with nucleophiles can be extremely regiospecific. 2-Pyridyloxiran (1) undergoes slow but clean hydration in water and various buffered solutions, the reactions being conveniently monitored by liquid chromatography on a bonded C-18 reverse phase column. For example, in $0 \cdot 1 \mathrm{M}$-phosphate buffer at $22^{\circ}$, the half-lives of $(1)(0.01 \mathrm{M})$ are $158,285,250$, and $68 \mathrm{~h}$,

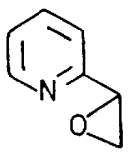

(1)

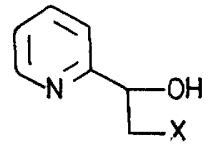

(2) $\mathrm{X}=\mathrm{OH}$

(3) $\mathrm{X}=\mathrm{OMe}$

(4) $X=C l$

(5) $\mathrm{X}=\mathrm{Br}$ at $\mathrm{pH} 1 \cdot 9,5 \cdot 0,8 \cdot 7$, and $13 \cdot 3$, respectively. The addition of divalent transition-metal ions $\left(10^{-4} \mathrm{M}\right)$ greatly increases the 
rate of hydration, the magnitude of the catalytic effect decreasing in the order $\mathrm{Cu} \Pi>\mathrm{Co}^{I I}>\mathrm{Zn}^{\mathrm{II}}>>\mathrm{Mn} I$.

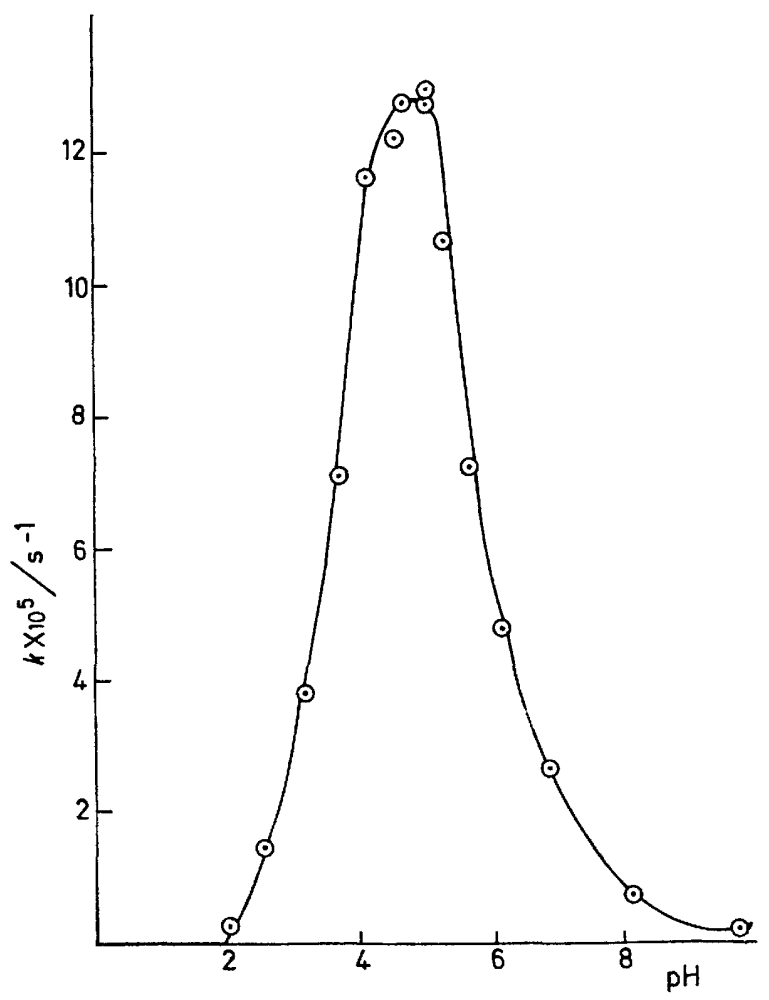

FIguRE. pH Dependence of the rate of copper-catalysed hydration of 2-pyridyloxiran $\left(10^{-2} \mathrm{M}\right)$ in $0 \cdot 1 \mathrm{M}$ phosphate with $10^{-4} \mathrm{M} \mathrm{CuSO}_{4}$ at $22^{\circ}$.

The rate of the copper-catalysed hydration is proportional to the copper concentration, and at low $\mathrm{pH}$ the reaction obeys pseudo-first-order kinetics. At high $\mathrm{pH}$ the rate decreases as the reaction proceeds, probably because the product acts as a tridentate chelating agent and removes the copper in a non-catalytic form. Thus the rate law for the reaction in $0 \cdot 1 \mathrm{M}-\mathrm{KH}_{2} \mathrm{PO}_{4}(\mathrm{pH} 5 \cdot 09)$ is: $-\mathrm{d}$ [epoxide] $/ \mathrm{d} t=$ $\left(k_{0}+k_{\mathrm{m}}\left[\mathrm{Cu}^{2+}\right]\right)$ [epoxide], where $k_{0}$ and $k_{\mathrm{m}}$, the rate constants for the uncatalysed and catalysed reactions, are $6.75 \times 10^{-7} \mathrm{~s}^{-1}$ and $1.261 \mathrm{~mol}^{-1} \mathrm{~s}^{-1}$, respectively.
The $\mathrm{pH}$-rate profile for the copper-catalysed reaction (Figure) shows a maximum rate occurs at a $\mathrm{pH}$ at or near the minimum of the $\mathrm{pH}$-rate profile for the uncatalysed reaction. Thus at $\mathrm{pH} 5 \cdot 1 \mathrm{Cu}^{2+}$ causes a rate acceleration of $1.83 \times 10^{4}$ fold. The observed rate decrease as the $\mathrm{pH}$ decreases from $\mathrm{pH} \mathbf{5 \cdot 1}$ is most reasonably attributed to protonation of the pyridine ring preventing copper binding. Correspondingly, the rate profile shows an inflection at $\mathrm{pH}$ ca. $3 \cdot 6-3 \cdot 7$, which is approximately the $\mathrm{p} K_{\mathrm{a}}$ of the epoxide as determined by direct titration. This interpretation also agrees with the observed lack of product inhibition at low $\mathrm{pH}$, where the product would be protonated. The hydration rate also decreases as the $\mathrm{pH}$ increases from $\mathrm{pH} 5 \cdot 1$, giving an inflection at $\mathrm{pH} c a \cdot \mathbf{5 \cdot 9}$. This decrease is less easily explained, but may be due to the formation of a catalytically inactive copper species such as the $\mathrm{HPO}_{4}-\mathrm{Cu}$ complex. ${ }^{2}$ The concentration of monomeric and dimeric hydroxocopper species should be negligible below $\mathrm{pH}$ $6 \cdot 5-7 .^{3}$

In methanol containing $10^{-4} \mathrm{M} \quad \mathrm{Cu} I \mathrm{I}$ the epoxide (1) $(0.01 \mathrm{M})$ reacts rapidly to give exclusively the $\beta$-monomethyl ether (3), with no detectable amount of the $\alpha$ methoxy-isomer. On the other hand in $\mathrm{MeOH}$ containing $0 \cdot 1 \mathrm{M} \mathrm{NaOMe}$, the epoxide (1) undergoes both $\alpha$ and $\beta$ attack in a $1: 2$ ratio, while in $\mathrm{MeOH}$ containing $0.1 \mathrm{M}$ toluene- $p$ sulphonic acid the ratio of $\alpha$ to $\beta$ attack is $85: 15$. A similar absolute selectivity for $\beta$ attack was observed in the copper-catalysed formation of the chlorohydrin (4) from (1) in phosphate buffers containing $\mathrm{Cl}^{-}$. With Tris- $\mathrm{HCl}$ buffer and copper, the diol (2) and the chlorohydrin (4) were formed in roughly equal amounts, but the $\alpha$-chloro-isomer of (4) could not be detected. Parallel results were also obtained using $\mathrm{Br}$ as a nucleophile. In this case the bromohydrin (5), an intermediate in the synthesis of the epoxide (1), was the only detectable isomer formed in the presence of copper, although both isomers were formed in aqueous $\mathrm{HBr}$. Thus at least in these three cases, and probably in the case of the hydration as well, the incoming nucleophile attacks exclusively at the $\beta$-carbon of the substrate.

We gratefully acknowledge financial support provided by the University of Kansas, Research Corporation, and the National Institutes of Health.

(Received, 18th November 1974; Com. 1398.)

${ }^{1}$ For examples see: D. A. Buckingham, F. R. Keene, and A. M. Sargeson, J. Amer. Chem. Soc., 1974, 96, 4981; R. P. Houghton and R. R. Puttner, Chem. Comm., 1970, 1270.

${ }^{2}$ H. Sigel, K. Becker, and D. B. McCormick, Biochem. Biophys. Acta, 1967, 148, 655.

${ }^{3}$ A. E. Martell, Pure Appl. Chem., 1968, 129. 